\title{
INDUSTRIALIZAÇÃO E URBANIZAÇÃO NO CENTENÁRIO DE PASSO FUNDO/RS - 1957
}

\author{
Industrialization and urbanization in the centenary of \\ Passo Fundo/RS - 1957 \\ Eduardo Roberto Jordão Knack*
}

\begin{abstract}
RESUMO
$\mathrm{O}$ presente trabalho objetiva analisar as relações entre industrialização e urbanização em Passo Fundo, Rio Grande do Sul, durante as comemorações do centenário do município em 1957. A partir da construção do imaginário da cidade como uma capital do planalto médio rio-grandense, o grupo no poder (vinculado ao Partido Trabalhista Brasileiro) durante a década de 1950 buscou a legitimação de um projeto político e econômico que passou a orientar as ações do poder público até a primeira década de século XXI. Dessa forma, é preciso discutir e elucidar as relações entre o desenvolvimento econômico e o campo do imaginário para investigar a historicidade das visões e projetos para o futuro da cidade que marcaram seu centenário, bem como para entender as consequências desse processo para economia não apenas de Passo Fundo, mas da região norte do estado. A defesa de uma industrialização baseada na produção de implementos agrícolas associada a um intenso êxodo rural provocado pela mecanização do campo trouxe significativas mudanças para o mundo urbano, marcando uma redefinição no traçado da cidade, a formação de bairros operários e populares que atestavam a falta de estrutura do município para absorver um grande contingente populacional em um curto período. Além de solucionar esses problemas, era preciso justificar as propostas, nesse sentido, a celebração dos cem anos foi um momento propício para isso, onde políticas públicas, projetos para economia municipal e afirmação de um imaginário coincidiram sob a orientação do poder público.
\end{abstract}

\footnotetext{
* Graduado e Mestre em História pela UPF. Doutorando em História pela PUC - RS. E-mail de contato: eduardorjk@yahoo.com.br.
} 
Palavras-chave: industrialização, urbanização, imaginário

\begin{abstract}
This article analyzes the relations between industrialization and ubarnization in Passo Fundo, Rio Grande do Sul, during the celebrations of the hundredth anniversary of the city, in 1957. The group in charge (linked to the Partido Trabalhista Brasileiro) during the decade of 1950 built the city imaginary as a "Plateau Capital" from Rio Grande do Sul and worked to legitimate a politic and economic project which was the guide to the government until the first decade of the XXI century. Therefore it is necessary to investigate the relations between the economic development and the imaginary in order to understand the historicity of the views and projects to the future of city that are important to the hundredth anniversary as well as to understand the consequence of this process to the economy not only in Passo Fundo but also in the north of the state. The fight for an industrialization based on the production of agricultural machines as well as the intense rural exodus due to the mechanization of the countryside brought a lot of changes to the city, as the new definition of the boards, the built of the popular and workmen neighborhoods which showed the lack of structure of the city to have too many people in a too short period of time. Thus it was necessary to solve these problems as well as justify the proposals. The hundredth anniversary was the perfect moment to do so when public politics, projects to the city's economy and the built of the imaginary were under the government guide.
\end{abstract}

Keywords: industrialization, urbanization, imaginary

\title{
Considerações iniciais
}

A comemoração de um centenário é um acontecimento marcante para uma cidade. $\mathrm{O}$ aniversário de cem anos constitui um momento onde uma comunidade não apenas pensa, define e/ou redefine sua(s) história(s), mas também seus projetos para o futuro. $\mathrm{O}$ que entra em jogo em uma celebração é o foco a ser dado a história e as utopias que circundam o presente. Os grupos envolvidos com o poder institucional geralmente colocam-se a frente da organização de aniversários municipais, selecionando os personagens importantes, os 
eventos marcantes, entre outros elementos, em função da conjuntura histórica, dos problemas e questões centrais do momento.

É na cidade que as comemorações de aniversários municipais se desenrolam, é, portanto, no espaço urbano que a história a ser legitimada, bem como os objetivos políticos e econômicos dos grupos a frente da organização das festividades são mostrados. Ricouer indica como o espaço habitado é formado por construções que podem ser entendidas como uma espécie de narrativa, pois formam um tipo de inscrição que é registrada no espaço material, onde o tempo trabalha de forma mais explicita o espaço em uma relação intertextual com outros elementos (tradição arquitetônica, planos urbanísticos, história dos grupos, entre outros). Uma cidade é marcada por diferentes temporalidades, trazendo em seu espaço permanências de épocas anteriores, mas também rupturas. É no interior do movimento dinâmico do mundo urbano da cidade que "tempo narrado e o espaço habitado estão nela mais estreitamente associados do que edifício isolado [...] seus espaços públicos, suas praças, justamente denominadas, convidam às comemorações e as reuniões públicas." 1

A elaboração de um Plano Diretor de Desenvolvimento Urbano (PDDU) em Passo Fundo representou a busca pela modernização ${ }^{2}$ e organização urbana em um espaço que enfrentou surtos de crescimento populacional, fenômeno associado ao desenvolvimento econômico e a mecanização agrícola que levou ao êxodo dos campos para a cidade. Em 1957 também é possível visualizar diferentes épocas inscritas a partir da arquitetura, onde edifícios modernos contrastavam com moradias insalubres, as praças e as ruas passavam por um processo de embelezamento enquanto os bairros no entorno do centro sofriam com o inchaço. O centenário colocou essas questões em evidência, exigindo do poder institucional a busca pelo controle e ordenação do que deveria ser celebrado, ser visualizado. O imaginário de Passo Fundo como capital do planalto

1 RICOEUR, Paul. A memória, a história, o esquecimento. Campinas: Editora Unicamp, 2007. p.159.

2 Modernização, nos discursos da década de 1950 em Passo Fundo, nos periódicos locais, no próprio PDDU, diz respeito a transformações urbanas, especialmente sobre a verticalização do espaço urbano, o crescimento populacional e respectivo aumento de edificações no centro e nos bairros, aceleração dos transportes, com intensa introdução de automóveis. 
era justificado por a cidade ser a mais moderna (referência ao processo de verticalização, abertura e melhoramento de ruas e avenidas, embelezamento de praças e logradouros e índices crescentes da construção civil) e industrializada do planalto médio riograndense, portanto, urbanização e industrialização eram entendidos como fatores que levariam o desenvolvimento ao município e região.

Baczko $^{3}$ indica que o imaginário proporciona esquemas coletivos de interpretações de experiências individuais, codificando expectativas e esperanças, atuando junto a memória coletiva e as representações de determinados grupos. Para Catroga ${ }^{4}$ o "imaginário da memória liga os indivíduos, não só verticalmente, isto é, a grupos ou entidades, mas também a uma vivência horizontal e encadeada do tempo." Em uma comemoração os grupos selecionam o que deve ser lembrado e o que deve se esquecido, utilizam a memória para legitimar projetos. As comemorações forçam uma coesão social, objetivam eliminar as representações que diferem do imaginário a ser legitimado.

Para estabelecer uma ampla compreensão do papel que a industrialização e a urbanização desempenham na consolidação do imaginário capital do planalto em Passo Fundo durante seu centenário é necessário compreender a conjuntura em que a cidade, o estado e o país se encontravam. Além de contextualizar historicamente a década de 1950, também é imprescindível tecer algumas considerações sobre a história de Passo Fundo para elucidar as seleções realizadas no presente (1957) sobre o que deveria ser lembrado, ser comemorado como história e sua relação com o projeto político econômico defendido pelo poder institucional.

\section{Da fundação do povoado à capital do planalto}

3 BACZKO, Bronislaw. Los imaginarios sociales memórias y esperanzas colectivas. Buenos Aires: Nueva Visón, 1991.p. 30.

4 CATROGA, Fernando. Memória, história e historiografia. Coimbra: Quarteto Editora, 2001.p. 28. 
A formação de um povoado no território onde viria à ser fundado o município ocorre a partir da atividade dos tropeiros que buscavam, ainda no século XVIII, novos caminhos para o transporte de cavalares e muares. O tropeirismo no sul com base na criação, transporte e comercialização de mulas. Estava intimamente relacionado à mineração no centro do país, destino de grande parte dos animais exportados. Essa atividade era realizada por peões, caboclos e escravos, que constituíram elemento populacional significativo na fundação do povoado nas primeiras décadas do século XIX, grupos que não aparecem nas publicações e representações da cidade em 1957. O estabelecimento do povoado a partir de 1820 ocorreu com a presença de luso-brasileiros, tropeiros e/ou militares, paulistas da comarca de Curitiba, em sua maioria.

Desde sua fundação no início do século XIX Passo Fundo caracterizou-se como um entreposto comercial cercado por fazendas de criação de animais (gado, mulas, porcos). Outras atividades econômicas também marcaram a vida da pequena vila, como a extração da erva mate dos ervais, extração de pedras, agricultura, criação de animais, entre outras. Porém, a região norte do estado ainda era a mais atrasada em termos econômicos, pelo menos até as primeiras décadas de 1900. Com a imigração (inicialmente, alemães, italianos e poloneses, seguidos de outras etnias), o desenvolvimento dos estabelecimentos comerciais ganha um grande impulso, estimulando a economia local. Esses estabelecimentos eram as chamadas vendas, que, para Tedesco ${ }^{5}$ eram o "espaço da intermediação mercantil, financeira e de sociabilidade na colônia". Essas vendas passam a ser o elo entre colonos e comerciantes, comércio que ocorria nas sedes urbanas das colônias que se formavam na região.

A economia passo-fundense, bem como de todo planalto médio, encontra um crescimento real apenas em 1898, quando ocorre a instalação da estrada de ferro $^{6}$, oferecendo uma possibilidade

5 TEDESCO, João Carlos. De olho na balança! Comerciantes coloniais do Rio Grande do Sul na primeira metade do século XX. Passo Fundo: Méritos: EST, 2008.p. 31.

6 Jacomelli indica que a construção de uma rede de transportes fazia parte de uma política do governo do estado levada a cabo pelo Partido Republicano Rio-Grandense (PRR) ligada a ideia de um desenvolvimento econômico autônomo e diversificado. Para isso era necessário 
adicional de escoamento da produção local e o contato direto com outras regiões do país e outras cidades do estado. O estímulo ao comércio foi notável, mas a passagem do trem também proporcionou a exploração de terras até então consideradas desabitadas (na verdade, eram habitadas por caboclos que viviam de uma agricultura de subsistência e nativos que estavam estabelecidos nas matas e campos do planalto antes dos primeiros luso-brasileiros chegarem), além da exploração da madeira, que aumentou consideravelmente. A "expansão da agricultura colonial em direção a essa região beneficiou-se da fertilidade do solo, e as áreas de mata foram cedendo lugar à agricultura", ${ }^{\text {, }}$, processo que configurou um êxodo rural inicial, pois desalojou um grupo considerável de pessoas que viviam dos ervais públicos e de uma agricultura rudimentar. De acordo com D'Avila :

No recenseamento realizado em 1900, o município possuía uma população de apenas 21.254 habitantes, sendo a população da cidade estimada em menos de duas mil pessoas. Em 1910 tendo sido contados apenas os domicílios (em número de 6.961) a população do município de Passo Fundo havia duplicado, de acordo com as estimativas.

Responsável pelas primeiras transformações urbanas significativas no município e pelo estímulo na economia da região, a estrada de ferro assinala a entrada de Passo Fundo em um período de transformações urbanas aceleradas, incluindo problemas típicos de

prover os nascentes núcleos urbanos com uma rede de transportes adequada, conforme a autora indica, a "situação acentuava a necessidade de se conectar o norte do estado, onde se formavam núcleos urbanos como Passo Fundo, Santo Ângelo e Palmeira das Missões, com Porto Alegre ou com o porto de Rio Grande." (JACOMELLI, Jussara. Políticas públicas e rede de transporte no norte rio-grandense (1889-1955). Passo Fundo: Editora UPF, 2011. p.113-116).

7 TEDESCO, João Carlos; SANDER, Roberto. Madeireiros, comerciantes $e$ granjeiros: lógicas e contradições no processo de desenvolvimento socioeconômico de Passo Fundo (1900-1960). 2.ed. Passo Fundo: UPF, 2005. p.46. 1996.p. 126.

8 D’AVILA, Ney Possapp. Passo Fundo terra de passagem. Passo Fundo: Aldeia Sul, 
uma cidade que não estava preparada para um grande crescimento populacional em poucos anos. A estação ferroviária desloca o centro, valorizando os espaços ao redor da atual Praça Marechal Floriano, proporcionando "o surgimento de bairros residenciais de classe operária que passaram a se desenvolver no seu entorno." 9 . Em 1957, como indica o Plano Diretor de Desenvolvimento Urbano (PDDU), as casas "insalubres" (muitas localizadas nesses bairros operários emergentes), que não condiziam com a visualidade da capital do planalto, eram consideradas um problema para a expansão e o embelezamento da cidade, constituindo mais um grupo (os pobres da cidade, que habitavam espaços até então pouco valorizados pela especulação imobiliária) que não ganha visibilidade durante as comemorações do centenário, mesmo formando uma parcela significativa de uma população que crescia aos saltos, conforme Gosch $^{10}$ indica:

A partir da década de 1920 a parte leste da cidade expandiu-se, dando a idéia de um Passo Fundo novo, ficando o Boqueirão considerado como cidade antiga. Em 1920, a população do município totalizava 65528 habitantes em 10542 domicílios, o que demonstra o crescimento do município, afirmando a sua importância no contexto das principais cidades do interior do estado.

É possível notar que o início do século XX configurou intensas transformações urbanas e econômicas. Cabe destacar que data desta época a construção da usina hidroelétrica do Taquari, promovendo a difusão da iluminação elétrica e fornecendo energia para as indústrias da região. Acompanhando o desenvolvimento da cidade, instala-se em 1912 a agência do Banco da Província do RS. Data também da primeira década de 1900 a fundação do Hospital da Caridade, em 1914, e do Hospital São Vicente de Paulo, em 1918, e a

9 GOSCH, Luiz Roberto Medeiros. Evolução urbana de Passo Fundo. In: WICKERT, Ana Paula. (org.). Arquitetura e urbanismo em debate. Passo Fundo: Editora UPF, 2005.p. 77.

10 GOSCH, Luiz Roberto Medeiros. Evolução urbana de Passo Fundo... p. 78-79. 
construção do quartel do exército, já em $1922 .{ }^{11}$ Na década de 1930 a produção agrícola é incrementada e a produção de milho, trigo e extração de madeira foram dinamizadas por uma rede de comerciantes que se formava e se beneficiava da facilidade de transporte com a ferrovia e posteriormente com as rodovias. Também é importante apontar os frigoríficos e matadouros da região, que, no decorrer da década de 1930, "contava com uma ampla estrutura frigorífica para suínos, uma das maiores do estado, e com um grande número de pequenos moinhos no meio rural e alguns maiores no meio urbano." 12

Mas é a década de 1940 que marca a consolidação do município como uma cidade central para a região norte. O que exemplifica essa afirmação são as constantes emancipações, marcando a perda de território, porém sem afetar o crescimento populacional, especialmente da área urbana, onde "a população passou de 31229 para 50 559, o que corresponde, em termos percentuais, a uma variação de 30,65\% para 54, 26\%."13 A década de 1940 ainda assinala a consolidação do acesso rodoviário para São Paulo, Rio de Janeiro e Porto Alegre, o que afirmou o município como um entroncamento rodo-ferroviário. ${ }^{14}$ É nessa conjuntura que Passo Fundo adentra a década de 1950, com a economia em pleno crescimento, facilitada por uma rede de transportes que estimulou as atividades agroindustriais, mas com problemas na área urbana derivado do significativo aumento populacional.

11 Ver: FERREIRA, Mariluci Melo; SIQUEIRA, Rosimar Serena. O contexto econômico e político de Passo Fundo do século XIX à década de 1930. In: DIEHL, Astor Antônio. (org.). Passo Fundo: uma história, várias questões. Passo Fundo: EDIUPF, 1998. p.78. Consultar também: MIRANDA, Fernando B. Severo; MACHADO, Ironita P. Passo Fundo: presentes da memória. Rio de Janeiro: MM Comunicações, 2005. p. 63,126,128.

12 TEDESCO, João Carlos; SANDER, Roberto. Madeireiros, comerciantes $e$ granjeiros... p.73.

13 GOSCH, Luiz Roberto Medeiros. Evolução urbana de Passo Fundo... p. 81.

14 Conforme Jacomelli (JACOMELLI, Jussara. Políticas públicas e rede de transporte...p. 206) indica, a consolidação das rodovias no norte do estado foi um processo que se estendeu desde 1920, ainda na primeira República, com a construção de estradas articuladas as ferrovias, até a década de 1950, mesmo assim, "ao se chegar à década de 1930 as regiões coloniais ainda estavam carentes de vias de comunicação e transporte." Em 1956, "Passo Fundo e Erechim fortaleceram-se como nós de uma rede viária ligando o Rio Grande do Sul com São Paulo e Rio de Janeiro, com alcance além do regional, ou seja, inter-regional.” 


\title{
Industrialização e urbanização em 1957
}

\begin{abstract}
A ênfase concedida à industrialização e a agricultura pode ser percebida pela análise da publicação Passo Fundo centenário guia turístico, literário e comercial, de 1957. Essa edição comemorativa circulou durante as atividades organizadas pela Comissão Pró Comemorações do Centenário $^{15}$, que tinha o prefeito Wolmar Salton ${ }^{16}$ como respectivo presidente. A capa do guia, contendo o Brasão Municipal (criado em função do centenário), exprime o imaginário capital do planalto e o sentido atribuído a esse título pelos organizadores das festividades, especialmente pelo poder político institucional. Na contracapa aparece a descrição da lei n. 340 de 1857, que emancipa o município, e, logo abaixo, a lei n. 720 de 1956, que cria o brasão, acompanhada de sua descrição. Segue uma parte da lei:
\end{abstract}

Escudo português, quadripartido, em secções, verde, amarelo, azul e laranja. Em chefe, campo subdividido em dois retângulos, verde e amarelo, representando o desenvolvimento econômico do passado (pinho), do presente (trigo), e atravessado por banda de gole azul, centrada pelo nome do Município em letras Brancas. Em campo de sinople, em laranja e azul, desenvolvimento econômico do presente e futuro (indústria) repousante no potencial hidrelétrico. Ao pé do escudo, banda de gole (vermelho), com letras brancas, do trinômio sobre o qual

15 Fundada em 28 de janeiro de 1957, “A Comissão Central Pró-Festividades Comemorativas do $1^{\circ}$ Centenário será composta de até 9 membros, presidida pelo Sr. Prefeito Municipal e tendo como Vice-Presidente o sr. Presidente da Câmara de Vereadores." (O’NACIONAL, 7 de fevereiro de 1957). Entre as principais realizações da comissão estão a construção dos pavilhões do centenário (Pavilhão da Indústria e do Trigo), onde se realizou a exposição industrial do município e a $7^{\circ}$ Festa do Trigo.

16 Em 1947 elegeu-se vereador pela coligação PTB-UDN, reeleito em 1951 pelo PTB. "Foi dele o projeto para a criação e instalação do Distrito Industrial de Passo Fundo [...], presidiu várias instituições do município, como: Associação Comercial, hoje ACISA; o Rotary Clube; o Centro das Indústrias da Região do Planalto." (NASCIMENTO, Welci; DAL PAZ, Santina Rodrigues. Vultos da história de Passo Fundo. Passo Fundo: Pe. Berthier, 1995. p.82). 
A própria caracterização do Brasão Municipal remete a uma elaboração temporal, histórica, já mirando um futuro. Trigo e a indústria, alimentada pelo potencial hidrelétrico, constituem o principal projeto político das elites políticas e econômicas do município nos anos 1950, a essência da palavra progresso no principal símbolo do centenário. A palavra progresso, constantemente usada nos discursos políticos e históricos naquele contexto remete, particularmente, ao crescimento econômico baseado na agroindústria. Mesmo exultando a indústria e a agricultura, pensando nos prognósticos futuros, são constatados problemas, como demonstra ofício enviado pelo prefeito Wolmar Salton ao secretário do estado, constituído de apontamentos sobre a situação do município, contando as seguintes dificuldades: falta de dados sobre a economia da região para planejamento econômico, baixa produtividade agropecuária e industrial, pedido de investimento em um "programa de ação que tivesse por objetivo modificar a técnica de produção", pois, de acordo com o prefeito, "os métodos usados pela maioria dos produtores empenhados nas atividades agrícolas e animais são muito rotineiros, primitivos e rudimentares." 18

É importante fazer uma referência a Koselleck ${ }^{19}$ e $\operatorname{Hartog}^{20}$, no que diz respeito à organização da temporalidade histórica de uma sociedade. Koselleck, refletindo sobre a modernidade e a possibilidade de se prognosticar situações políticas determinadas, realizando previsões calculáveis, indica que o "prognóstico produz o tempo que engendra e em direção ao qual ele se projeta", um tempo que sempre escapa ao presente, mas que pode ser "capturado" momentaneamente pela capacidade prognostica dos indivíduos.

17 OLIVEIRA, Pery de. Passo Fundo centenário guia turístico, literário e comercial. Passo Fundo: Oficinas Gráficas do Instituto Social Pe. Berthier, 1957.

18 OLIVEIRA, Pery de. Passo Fundo centenário...p. 21.

19 KOSELLECK, Reinhart. Futuro passado: contribuição à semântica dos tempos históricos. Rio de Jaeiro: Contraponto: Ed. Puc-Rio, 2006. p. 32-33.

20 HARTOG, François. Tempo e história: “como escrever a história da França hoje?”. In: História Social. Campinas, nº3, 1996.p. 129. 
Hartog elabora a noção de regime de historicidade "como uma formulação erudita da experiência do tempo que, em troca, modela nossa forma de dizer e viver nosso próprio tempo." A comemoração de um centenário, organizada pelo poder político institucional, implica previsões que estão ligadas à percepção dos indivíduos sobre a própria história. Essa percepção da historicidade em Passo Fundo é marcada pela ideia de progresso, movido pela agricultura com o trigo, mas tendo a indústria como alavanca para o futuro. Essa visão está intimamente vinculada com o desenvolvimentismo que marcava o Brasil na década de 1950, como veremos no próximo item.

Em relação à indústria, a publicação Passo Fundo centenário menciona a fabricação de implementos agrários como elemento central da economia, os hotéis (considerados como "indústria") e a fabricação de materiais de construção que encontravam crescimento "justificável pelo desenvolvimento acelerado da cidade e amplas possibilidades de exportação para toda uma vasta zona." ${ }^{21}$ A consideração do setor hoteleiro como indústria, e não uma atividade de prestação de serviços ou comercial, mostra a vontade do poder político em apresentar um grande índice de indústrias no município como um elemento que afirmava Passo Fundo como capital do planalto. Especificamente sobre a indústria e o comércio, o guia traz os seguintes pontos:

Passo Fundo conta com indústria florescente, protegida, agora, pode-se dizer, por abundante energia elétrica, provinda das usinas de Capingui e Ernestina. Lei municipal ampara, por outro lado, a instalação de indústrias em nosso Município "isentando do pagamento de Impôsto Municipal tôdas aquelas que se instalarem e que não tiverem similares."22

A cidade promovia incentivos fiscais e abundante energia elétrica como pontos positivos para a instalação de indústrias no 
município. Também se fazia propaganda da construção de um distrito industrial próximo à estação ferroviária e uma estrada (a ser construída) que ligaria Passo Fundo a Porto Alegre. Entre as indústrias que merecem menção nas páginas do guia estão dois frigoríficos, a cervejaria Brahma, dois moinhos de trigo e, em destaque, contendo uma foto no final da página e uma descrição mais extensa de suas atividades, a fábrica de pregos Hugo Gerdau. Em seguida, entre as páginas 35 e 40, é conferido grande destaque a agricultura. Nestas páginas, divididos em dois subtítulos (Agricultura e $A$ Conquista do Campo), é feita uma apologia ao cultivo do trigo, a grande aposta cidade para a economia, inclusive como propulsor de uma indústria de implementos agrícolas. Abaixo do subtítulo Agricultura, consta uma citação de Getúlio Vargas: "Plantai trigo, ele é a glória dos campos, a fartura do lar e a riqueza da pátria". Logo abaixo, uma foto de uma lavoura de trigo e um trator em atividade, com a seguinte legenda: "Preparando a terra mecanicamente" 23 , representando a relação entre a indústria e a agricultura. Na página 37 é feita alusão à formação de uma cooperativa, dirigida por um "industrialista", para dar suporte à produção do trigo:

A fim de corresponder às exigências do grande desenvolvimento lavoureiro que se verifica atualmente e para defender os interesses da triticultura local, foi fundada a "Cooperativa Tritícola do Planalto Ltda.", em cuja presidência se encontra o Sr. Mário Menegaz, forte industrialista, um dos maiores entusiasta locais do plantio do cereal-rei e ex-prefeito municipal. ${ }^{24}$

Abaixo dessa citação, aparece uma pequena foto de Mário Menegaz $^{25}$, e duas fotos de plantações de trigo, a primeira com uma

23 OLIVEIRA, Pery de. Passo Fundo centenário...p. 35.

24 OLIVEIRA, Pery de. Passo Fundo centenário...p. 37.

25 Mário Menegaz foi eleito vice-prefeito em 1951 pela coligação PTB/PSP/PR, assumindo a prefeitura depois da eleição de Daniel Dipp (prefeito pela mesma coligação) para o legislativo estadual pelo PTB. (DAMIAN, Marco Antonio. Eleições em Passo Fundo: dados históricos. Passo Fundo: Berthier, 2010. p.42). A empresa Menegaz S/A nasce inicialmente como 
criança em primeiro plano com a legenda "o trigo cresce verde esperança", e a segunda com um adulto em primeiro plano, com a legenda "... e amadurece amarelo-ouro." 26 Percebe-se toda uma construção simbólica, que contribui para a formação de um imaginário em torno do progresso que o trigo e a industrialização estão proporcionando, e vão proporcionar à cidade, em futuro que existe nas previsões do poder público e das elites econômicas locais a frente desse processo. De fato, ocorre em 1957 a construção de uma justificativa histórica para a cultura do trigo, articulando passado, associado aos primórdios do povoado e a uma personalidade fundamental para o partido político dominante nos anos 1950, Getúlio Vargas, patrono do PTB.

O historiador homenageado em 1957, Francisco Antonino Xavier e Oliveira, que, além de servir como referência sobre a história da região ao Passo Fundo guia turístico, literário e comercial, recebe um artigo nessa publicação que o aponta como Heródoto da história passo-fundense. Xavier e Oliveira publica o livro Rememorações do nosso passado no centenário, com um capítulo intitulado $O$ trigo em Passo Fundo, onde remonta, a partir de dados da Câmara Municipal, a plantação do cereal em " 1858 , ano em que, na primeira estatística agrícola organizada pela mesma edilidade, figura com uma plantação de 1.600 litros." ${ }^{27}$ Finaliza o capítulo escrevendo sobre a renovação tecnológica que esta cultura recebe com a fundação da Estação Experimental de Engenheiro Englert pelo governo federal, em 1937, "para desenvolver a cultura do trigo, manifestando a participação pública na pesquisa agropecuária brasileira e no incentivo na produção de trigo."28

A formação de cooperativas nesse período sinaliza a necessidade de apoio mútuo entre pequenos e médios produtores frente à crise do trigo que iniciava no país devido à interferência dos

uma fundição nos anos 1920, no final da década de 1930 passa a fabricar moinhos, em 1940, passa a produzir também cilindros para moagem e máquinas de limpeza para grãos e motores para veículos, e "a partir do ano de 1956, começa a produzir somente implementos agrícolas." (NASCIMENTO, Welci. Conheça Passo Fundo, tchê! Passo Fundo: Pe. Berthier, 1992. p.73-74).

26 OLIVEIRA, Pery de. Passo Fundo centenário... p.37.

27 XAVIER E OLIVEIRA, Francisco Antonino. Rememorações do nosso passado. Porto Alegre: Oficinas Gráficas da Imprensa Oficial, 1957.p. 53.

28 XAVIER E OLIVEIRA, Francisco Antonino. Rememorações... p.56. 
produtores de trigo norte-americanos. Tedesco e Sander ${ }^{29}$ resumem o período entre 1956-67: "crise do trigo, surgimento de cooperativas tritícolas, consolidação do binômio trigo-soja e da categoria econômica dos granjeiros - grandes proprietários de terra na região." Passo Fundo celebrava o trigo como grande aposta, mas o quadro nacional não era favorável e a nível local iniciavam-se transformações nas propriedades agrícolas. Isso não significa que os prognósticos do poder público foram percebidos como "errados", pois a transição do trigo para soja possibilitou a manutenção das atividades industriais e comerciais ligadas à agricultura, a emergência dos granjeiros não altera drasticamente a produção industrial destinada a esse setor. Koselleck $^{30}$ indica que um "prognóstico falho, por outro lado, não pode ser repetido nem mesmo como erro, pois permanece preso a seus pressupostos iniciais." A possibilidade de manter um planejamento político-econômico a partir da agroindústria não foi abalada, o que significa a continuidade de uma percepção histórica que encontra fundamento nos argumentos de Xavier e Oliveira, incorporada aos discursos políticos durante o centenário.

O prognóstico implica um diagnóstico capaz de inscrever o passado no futuro. Por essa qualidade futura continuamente garantida ao passado é possível tanto assegurar quanto limitar o espaço de manobra do Estado. À medida que o passado só pode ser experimentado porque ele mesmo contém um elemento de futuridade - e vice-versa - , a existência política do Estado é tributária de uma estrutura temporal que pode ser entendida como uma capacidade estática de movimentação. ${ }^{31}$

Essa característica de circularidade histórica dos prognósticos garante a possibilidade do progresso sobre as mesmas bases que fundamentaram sua ideia inicial, justificado historicamente por

29 TEDESCO, João Carlos; SANDER, Roberto. Madeireiros, comerciantes $e$ granjeiros... p.92-93.

30 KOSELLECK, Reinhart. Futuro passado...p. 32.

31 KOSELLECK, Reinhart. Futuro passado...p.36. 
Xavier e Oliveira em 1957. A previsão de industrialização baseada na produção agrícola não é afetada, isso vai ao encontro da noção de caráter estático dessas previsões, conforme Koselleck indica. Mesmo sendo circular, com o passado alimentando o futuro, e vice-versa, sua continuidade é mantida, apesar de mudanças circunstanciais (crise do trigo, passagem para soja, por exemplo), ou seja, a aposta nesse prognóstico limita a ação do estado, em função de investimentos tanto materiais (aplicação de capitais, auxílio na instalação da empresas, auxilio a agricultura, etc) quanto simbólicos, como no caso da construção do imaginário capital do planalto que marcou o centenário, caracterizando uma capacidade estática de movimentação.

O que ocorre é que a cultura do trigo havia recebido grandes investimentos técnicos que aprimoraram sua produção desde a década de 1930, como visto. Sua cultura também foi facilitada por um processo sinérgico, onde coincidiram diferentes atividade econômicas. Primeiro, a extração da madeira proporcionou a limpeza dos campos e o desalojamento de um grande contingente de camponeses (que migrou para as cidades formando um contingente de mão-de-obra disponível para a indústria), favorecendo a plantação de grãos em pequenas e médias propriedades, estimuladas pelo governo federal a partir de 1930, especialmente o trigo. Nesse processo, ocorre uma articulação entre colonos e comerciantes, contribuindo para a geração de capitais aplicados em outras atividades, como indústrias, por exemplo, estimulando ainda mais o desenvolvimento urbano. Nos anos 1950, ano das cooperativas e dos grandes granjeiros, as principais questões sociais e econômicas, apropriação da terra e inchaço urbano, encontram-se associadas:

Esses processos constituíram a chamada "economia agrícola" e o "perfil agrícola" da região, bem como os processos sociais agrários; contribuíram para o inchamento urbano e a formação de um contingente proletário urbano; colaboraram na diferenciação interregional (Campanha - pecuária - , Serra/norte - 
agricultura), de regiões de (agro)industrialização e de vazios econômicos e demográficos. ${ }^{32}$

A cultura agrícola mudou nesses processos indicados pelos autores, mas o apelo à industrialização permaneceu constante, embalado pelo desenvolvimentismo que levantava a bandeira da indústria em nível nacional como vetor do desenvolvimento econômico. As relações entre industrialização e urbanização em Passo Fundo são claras e aparecem como questões marcantes no Plano Diretor de Desenvolvimento Urbano (PDDU) elaborado em 1953 e aprovado/lançado em 1957, bem como previsões sobre o futuro do desenvolvimento urbano baseadas na visão de progresso própria da conjuntura. $\mathrm{Na}$ introdução do $\mathrm{PDDU}$, é descrito seu principal objetivo:

[...] ser verdadeiramente realista, sendo necessário que seja um Plano plenamente adaptado as condições existentes em nosso país e ás previsíveis condições futuras. Seus princípios devem ser válidos para a situação atual e capazes e fornecer aos cidadãos progressistas de Passo Fundo uma eficiente para auxiliá-los a superá-la. No processo de transformação pela qual passará a cidade, se forem concretizados os projetos rodo-ferroviários existentes, será necessário um Plano suscetível de continuar atuando devidamente nas novas condições. ${ }^{33}$

O Plano Diretor pretendia levar em consideração o futuro. Deveria lançar diretrizes para o crescimento futuro do município, observando a potencialidade da cidade se tornar um entroncamento rodo-ferroviário. Mas também apresenta uma retrospectiva histórica da fundação da cidade e dos principais acontecimentos que alteraram

32 TEDESCO, João Carlos; SANDER, Roberto. Madeireiros, comerciantes $e$ granjeiros... p.93.

33 PAIVA, Edvaldo, et. al. Passo Fundo plano diretor. Porto Alegre: Imprensa Oficial do Estado do Rio Grande do Sul, 1953. p.8. 
profundamente a configuração urbana, como a instalação da estrada de ferro, que forçou o alinhamento de moinhos, madeireiras e metalúrgicas, entre outros estabelecimentos comerciais, ao longo dos trilhos. Também atribui importância à rodovia que liga Passo Fundo a Porto Alegre, passando por municípios como Marau, o que estimulou o comércio e a indústria da madeira em todo norte do estado.

Entre essa rodovia e a estrada de ferro, a cidade começou a crescer, e, de acordo com os autores do plano, como resultado, "surgiu, do dia para a noite, o núcleo residencial operário denominado 'Vila Rodrigues'. A implantação da cervejaria e de metalúrgicas e fábricas carroceiras", entre depósitos e serrarias, o que levou a "formação de uma zona de habitantes proletários, em terrenos de má qualidade e baixo preço." ${ }^{34}$ Essa zona proletária da cidade, que encontrou um crescimento intenso, não faz parte da visualidade urbana da capital do planalto, de acordo com o Passo Fundo centenário de 1957, que tem um capítulo intitulado $O$ município ilustrado, que estabelece uma narrativa visual apenas da região no entorno da praça Marechal Floriano, da Rua Moron, da Rua Bento Gonçalves e Av. Brasil (centro da cidade até hoje). As diferentes épocas inscritas no espaço urbano de Passo Fundo não foram totalmente representadas, uma vez que a edição comemorativa prioriza o espaço central, centro comercial e financeiro, deixando de lado as zonas operárias.

Não obstante, a previsão do plano parte do pressuposto de que Passo Fundo, em 1957, já figurava com centro regional do norte do estado. Associando o crescimento da cidade a uma visão histórica que atribui à ferrovia o grande fator de desenvolvimento do município (e região), o planejamento apostava que a cidade seria um entreposto, assumindo função de mercado regional, exportando produtos agroindustriais e importando outros produtos necessários para o consumo urbano. A partir dessa concepção, a previsão é que como "centro regional de uma população de 700 mil habitantes e apoiada em sua qualidade de entreposto comercial, ela poderá criar um parque industrial vigoroso e sólido." 35 A partir da constatação do presente 
(justificado historicamente), é prognosticado um futuro, que orienta a elaboração do PDDU. Frente a isso, um dos principais problemas identificados pelos urbanistas é como gerir o crescimento populacional, proporcionar uma base sólida para a industrialização e manter a qualidade estética das moradias. Indicando como o grosso da população cerca de 600 ferroviários, 1.200 soldados e 1.800 operários, o plano informa que

[...] a população de Passo Fundo se aloja, em sua maioria, em más condições. Mantém-se grande número de vivendas obsoletas, principalmente ao longo da avenida (em maior quantidade desde o Boqueirão até a linha férrea - parte mais antiga da cidade). São imóveis antiqüíssimos, em mau estado de conservação, habitados por famílias de classe média (e mesmo os de peor estado, por elementos ainda mais pobres, os quais imprimem um aspecto de decadência à várias partes da cidade. ${ }^{36}$

Essa população não aparece na visualidade urbana de Passo Fundo legitimada no centenário de Passo Fundo. O espaço de experiência em que os grupos que estavam no poder (vinculados ao poder executivo municipal, ao Partido Trabalhista Brasileiro) tinha como orientação afirmar a cidade como uma capital do planalto. As vivendas obsoletas, os imóveis antigos em mau estado de conservação, pertencentes aos operários e trabalhadores, não encontram espaço no imaginário urbano afirmado em 1957. A expectativa era da construção de uma cidade organizada, ordenada, adequada para o crescimento, para investimentos externos e industriais. Ocorre um choque entre diferentes temporalidades inscritas, materializadas no espaço urbano. Esses grupos representam uma velha Passo Fundo, mais pobre, mais parecida com a vila que foi um dia. São reminiscências do século XIX. O horizonte de expectativas que o poder político-econômico tinha em vista para cidade está assentado em uma outra temporalidade, conectado com o

36 PAIVA, Edvaldo, et. al. Passo Fundo plano diretor...p.34. 
progresso, com o futuro. O centro da cidade, seu cartão postal, não podia mais conviver com esses elementos do passado, ou mesmo com a pobreza arquitetônica. Enquanto a publicação que homenageia o centenário é um instrumento fundamental do imaginário, que apaga conflitos sociais e afirma a cidade como um centro regional, em perfeita organização, propício ao crescimento, o Plano Diretor é o instrumento que objetiva tornar isso realidade.

Entre as soluções encontradas, esta a divisão da cidade em zonas, assim, seria criada uma zona industrial, porém, flexível, não limitando o estabelecimento de indústrias apenas a área estabelecida, o que permitiria seu crescimento indefinido, e limitando zonas para o estabelecimento de habitações para operários. Foram criadas mais quatro zonas que correspondem à determinada função, como a de ruas residenciais, estendida as áreas próximas ao centro, uma zona para as atividades comerciais, a zona do centro tradicional, onde seriam permitidas todas as atividades, menos as industriais, uma zona onde seriam incluídos usos de depósitos e pequenas indústrias. E como eixo da urbanização estaria o esquema viário principal, constituindo grandes vias de acesso e travessia da cidade, onde estava previsto o possível crescimento a cidade e a necessidade da expansão de vias de grande tráfego.

Concordando com Carvalho ${ }^{37}$, "a idéia-mestra do planejamento de 1953 estava na necessidade de projetar a cidade para o crescimento populacional que iria presenciar nas décadas seguintes", levando em conta a melhoria do aspecto plástico da cidade "propondo novas formas de ocupação para o espaço público existente, fixando diretrizes de ocupação para o crescimento urbano e para o estabelecimento de novos loeteamentos. ${ }^{38}$ A busca pelo ordenamento do espaço urbano levou o poder político local a construir um instrumento que correspondia ao prognóstico de um futuro onde Passo Fundo assumiria, definitivamente, o posto de capital do planalto, a partir da complementaridade entre industrialização e a produção agrícola.

37 CARVALHO, Haroldo Loguercio. Passo Fundo do centenário ao sesquicentenário: que significados? In: BATISTELLA, Alessandro. (org.). Passo Fundo, sua história. Passo Fundo: Méritos, 2007.p. 416.

38 GOSCH, Luiz Roberto Medeiros. Evolução urbana de Passo Fundo... p. 83. 


\section{Considerações finais: desenvolvimentismo e regime de historicidade}

Hartog comentando sobre os regimes de historicidade e escrita da história aponta que o regime onde o passado esclarecia o futuro se desfez com a modernidade, onde "não é mais o passado que deve esclarecer o futuro, mas, inversamente, cabe ao futuro esclarecer o passado." ${ }^{39}$ O desenvolvimentismo no Brasil é uma faceta do regime de historicidade moderno, marcado por uma experiência temporal onde o passado passa a ser considerado ultrapassado. $\mathrm{O}$ passado usado para explicar/justificar os prognósticos futuristas implica uma ruptura com a história, um afastamento da ideia de que as experiências passadas podem ser repetidas. Enquanto formulação erudita da experiência do tempo, é possível definir o moderno regime de historicidade do século XX como um futurismo que "deve ser entendido aqui como a dominação do ponto de vista do futuro. Este é o sentido imperativo da ordem do tempo: uma ordem que continua acelerando ou se apresentando como tal." ${ }^{40}$

$\mathrm{O}$ futurismo que impregnava o desenvolvimentismo brasileiro é permeado de um otimismo econômico e político que dava margem aos prognósticos realizados no centenário de Passo Fundo. É possível relacionar as comemorações realizadas em 1957 com desenvolvimentismo do governo de Kubitschek ${ }^{41}$, bem como outros discursos e ideias de modernização e progresso que permeavam a sociedade naquele momento. A ênfase na industrialização como base nas previsões futuras só pode ser plenamente compreendida à luz da realidade do estado e do Brasil na década de 1950. Pesavento indica

39 HARTOG, François. Tempo e história...p. 129.

40 HARTOG, François. Regimes de historicidade: presentismo e experiências do tempo. Belo Horizonte: Autêntica Editora, 2013. p. 141.

41 Juscelino Kubitschek é um exemplo do regime de historicidade moderno, onde o futuro ilumina a história. Seus discursos são impregnados com essa percepção, como demonstra $O$ Brasil em marcha, onde o presidente aponta o desenvolvimento como "salvação nacional" e o que estava sendo realizado para isso: "As obras básicas que estão sendo promovidas em tempo recorde visam a não permitir que permaneçamos num atraso irrecuperável. Estamos estabelecendo os meios, as condições de podermos andar mais depressa." (KUBITSCHEK, Juscelino. O Brasil em Marcha. Impr. Nacional, 1958. p. 13). O próprio slogan de sua campanha, "50 anos em cinco", é uma marca dessa aceleração e da importância dos prognósticos futuros nas ações do governo. 
que, após a Segunda Guerra Mundial, a indústria aparece como o novo setor de ponta da economia nacional, perspectiva que é gerada ainda durante o Estado Novo com a emergência do nacionaldesenvolvimentismo e, durante a experiência democrática, essa política "oscilou entre uma tendência de prosseguir na linha de afirmação do desenvolvimentismo nacional autônomo e a corrente de associação ao capital estrangeiro". ${ }^{42}$

É importante citar as considerações de Fonseca ${ }^{43}$. De acordo com a definição do autor, quatro elementos, ou correntes de ideias, definem e originam o conceito "desenvolvimentismo": industrialização, intervencionismo pró-crescimento, nacionalismo e positivismo. Desenvolvimentismo e conceitos como modernização, progresso, dão sentido a ação do governo. Apontar o positivismo como um aspecto originário do desenvolvimentismo confere uma importância significativa a política rio-grandense e explica a emergência desse ideário durante o Estado Novo, sob o governo Vargas. Nesse sentido, mesmo que as propostas dos grupos que organizaram as comemorações em 1957 não fossem plenamente ao encontro do desenvolvimentismo, se alinhavam a determinadas características dessa corrente.

Pereira aponta a década de 1930 como o período da decolagem do desenvolvimento brasileiro, propiciando o que define como a revolução industrial brasileira que ocorre a partir da "destituição do poder da oligarquia agrário-comercial brasileira, que por quatro séculos dominou o Brasil." ${ }^{44} \mathrm{O}$ autor refere-se, no caso de 1930, a oposição entre uma aristocracia agrária e as classes médias brasileiras que apostavam na vocação agrária do país, em particular a cafeicultura. O governo Vargas não abandona a agricultura, e é justamente a política de defesa do café que gera uma alta de aproximadamente $50 \%$ nos preços dos produtos manufaturados importados, o que coincidiu com uma queda nos preços internos dos 1985.p. 94-95.

42 PESAVENTO, Sandra J. História da indústria Sul Rio Grandense. Guaíba: Riocell,

43 FONSECA, Pedro Cezar Dutra. Gênese e precursores do desenvolvimentismo no Brasil. In: Pesquisa \& Debate. São Paulo, v.15, n.2(26), 2004.p. 227.

44 PEREIRA, Luiz Carlos Bresser. Desenvolvimento e crise no Brasil História, Economia e Política de Getúlio Vargas a Lula. 5.ed. São Paulo: 2003.p. 41-42. 
mesmos artigos, estimulando o consumo e o investimento de empresários no setor industrial. Em 1931 o governo, influenciados pelos industriais, proíbe a importação da maquinarias para indústrias consideradas em "estado de superprodução", com o objetivo de proteger a indústria têxtil. ${ }^{45}$ Mas essa ação afetou a economia como um todo:

Novos investimentos, em novos setores, foram instalados. As fábricas geralmente começavam como oficinas. O pequeno capital necessário era, na maioria das vezes, levantado entre os membros da própria família. Como o reinvestimento dos lucros, porém, logo se expandiam. ${ }^{46}$

Essas indústrias iniciavam geralmente a produção de bens de consumo simples, pois exigiam maquinários pouco sofisticados que já eram fabricados no Brasil. A partir de um olhar aproximado às relações socioeconômicas do planalto médio gaúcho é possível perceber esse quadro e compreender o argumento inicial que guiava os prognósticos que apostavam no desenvolvimento econômico a partir da relação entre agricultura e indústria de implementos agrícolas. No caso da região de Passo Fundo, é possível apontar uma produção inicial baseada na agricultura (alimentos), agropecuário (criação de porcos, especialmente) de onde derivavam outros produtos, como a banha e a extração da madeira, por exemplo. Da associação entre as colônias e o comércio nas zonas coloniais sulinas surgiram empreendimentos que levaram a pequenas indústrias, como frigoríficos e moinhos. Pereira conclui que:

Ao findar a Guerra, podemos afirmar que a indústria leve ou básica de consumo estava instalada no Brasil. A partir dessa época teria início o desenvolvimento de indústrias

45 PEREIRA, Luiz Carlos Bresser. Desenvolvimento e crise no Brasil...p. 46. 46 PEREIRA, Luiz Carlos Bresser. Desenvolvimento e crise no Brasil...p. 46-47. 
de bens de consumo mais complexas, como é o caso de eletrodomésticos. Seria também dado mais impulso às indústrias de base e às de bens de produção. ${ }^{47}$

No caso do planalto médio, emergem as indústrias de implementos agrícolas, produzindo maquinários mais complexos, tendo como consumidores agricultores das zonas coloniais do estado e de outras regiões do Brasil. Assim, quando ocorre o que Pereira denominou como "consolidação do desenvolvimento industrial" entre 1956 e 1961 (marcada pela presença de Juscelino Kubitschek na presidência), Passo Fundo já estava inserida em uma lógica econômica inter-regional, facilitada por sua condição de entroncamento rodo-ferroviário. Para Pesavento, o governo de Kubitschek marca a passagem de uma indústria de bens de consumo leve para uma indústria pesada e "os agentes deste processo de expansão da indústria no país foram o Estado e o capital estrangeiro, que se viu estimulado a investir maciçamente no país." 48 A justificativa apresentada para essa opção era a necessidade de uma evolução técnica, estimulando as indústrias mais complexas que passam a figurar como carro-chefe da economia brasileira.

Mas essa mudança de rumo não correspondeu a um desestimulo das indústrias de bens de consumo não-duráveis, pois o período em questão conheceu um crescimento de empregos com investimentos de capital estrangeiro, levando ao aumento da necessidade de consumo desses bens, e "as empresas tradicionais, para não sucumbirem diante dos padrões mais avançados de tecnologia e do aumento da escala de produção, foram levadas a modernizarem-se também." 49 Os estados do centro-sul foram privilegiados com esse processo, pois é, sobretudo no Rio de Janeiro e, especialmente em São Paulo, que o capital estrangeiro e as indústrias pesadas se instalaram, o que acarretou uma relação entre a economia gaúcha e o parque industrial da região centro-sul que, com o tempo, mostrou-se desigual.

47 PEREIRA, Luiz Carlos Bresser. Desenvolvimento e crise no Brasil...p.52. 48 PESAVENTO, Sandra J. História da indústria Sul Rio Grandense...p. 95. 49 PESAVENTO, Sandra J. História da indústria Sul Rio Grandense...p.96. 
Pesavento indica que o período da redemocratização até 1964 no Rio Grande do Sul marca uma redefinição do caráter da economia para se adequar à nova realidade do país em um momento em que a indústria gaúcha apresentava uma melhor participação na economia na esteira do baixo desempenho do setor agrícola. Para a autora o estado "acompanhou o processo geral brasileiro na década de 50, na qual foi reduzida a participação relativa da agricultura na composição da renda interna e aumentou a da indústria." ${ }^{, 50} \mathrm{Na}$ região do planalto médio, agricultura e indústria estavam relacionadas, e o crescimento do setor secundário não foi suficiente para cobrir o mau desempenho da agricultura, que pode ser associada à crise da produção de trigo no final da década de 1950, mas a íntima relação entre o campo e a indústria era expressa na mecanização das lavouras (as propriedades agrícolas consumiam maquinários que, em parte, já eram produzidos na própria região), que, juntamente com a formação dos granjeiros, levaria a intensas ondas de êxodos rurais que atingiriam o seu auge em 1970. Isso proporcionou um inchaço urbano, aumentando o contingente de trabalhadores nas cidades que empreendiam projetos de modernização urbana para resolver problemas gerados pelo crescimento populacional. Essas alterações não se limitam à economia, mas ao próprio ritmo de vida dos indivíduos e da sociedade. Para Singer ${ }^{51}$ :

O estilo de vida urbano é um produto do capitalismo industrial, que se transforma cada vez que novos produtos são lançados no mercado. O automóvel, a televisão, o telefone, a geladeira e centenas de outros produtos caracterizam um padrão de vida que constitui a razão de ser do "desenvolvimento" para a maioria da população.

50 PESAVENTO, Sandra J. História da indústria Sul Rio Grandense...p.97-98.

51 SINGER, Paul. Interpretação do Brasil: uma experiência histórica do desenvolvimento. In: FAUSTO, Boris. (dir.). O Brasil republicano: economia e cultura (19301964), vol.4. 3. ed. Rio de Janeiro: Bertrand Brasil, 1995.p. 223. 
Embora Singer restrinja o habitante da urbe ao desenvolvimento do capitalismo industrial, seu comentário mostra a percepção do autor sobre como a industrialização, principal elemento do desenvolvimento brasileiro do período, imprimiu transformações mais profundas, naquilo que chamou de padrão de vida da população. O período 1956-1967, para Singer, constitui o auge da "aceleração" e do "desenvolvimento" da indústria e da sociedade. No que tange a urbanização, a construção de Brasília é o caso exemplar do que ocorria o Brasil, tanto na afirmação do desenvolvimentismo, como no que tange aos problemas derivados do crescimento desenfreado das cidades brasileiras.

A fundação e concepção de Brasília é o ponto culminante de décadas de tentativas de implantação no meio urbano das cidades brasileiras das características de exclusão e marginalização apropriadas fragmentariamente das cidades geradas pelo capitalismo industrial europeu e norte-americano, ou adequadas a ele e à gramática social calcada em padrões burgueses de diferenciação e controle sistêmico para as diferentes dinâmicas das diferentes sociedades urbanas. ${ }^{52}$

Como Ricoeur aponta, nas cidades, é possível identificar a inscrição de diferentes épocas nos espaços que vão se constituindo no transcorrer do desenvolvimento urbano. Brasília nasce como a visão da modernidade do país, simbolizando a interiorização e união da economia, deveria irradiar o germe do futuro nas outras cidades. Porém, como Marins percebe, desde o seu projeto inicial, a nova capital já trazia a marca da exclusão de grupos que não encontravam espaço no imaginário de um Brasil moderno, pois a "implantação do projeto urbanístico do plano piloto de Brasília desconheceu mesmo aqueles numerosos operários que a construíram." 53

52 MARINS, Paulo César Garcez. Habitação e vizinhança: limites da privacidade no surgimento das metrópoles brasileiras. In: NOVAIS, Fernando A. (Coord.). História da vida privada no Brasil República: da Belle Époque à era do rádio. V.3. São Paulo: 2006.p. 211.

53 MARINS, Paulo César Garcez. Habitação e vizinhança...p. 210. 
O grande símbolo do desenvolvimentismo não concedeu espaço para o grande contingente de operários e trabalhadores que participaram da sua construção, ou que migraram para a capital em busca de uma vida próspera. Os prognósticos de futuro que se originaram de uma visão desenvolvimentista parecem não ter levado em conta aqueles que não coincidiam com seu ideal de modernidade. Isso é constatado em Brasília, como também é constatado no planejamento urbano de Passo Fundo dos anos 1950. A grande preocupação das elites brasileiras em relação aos problemas urbanos era a "fluidez dos arranjos espaciais", que tornava instável a sociedade, portanto, regular, ordenar os espaços era vital. Brasília foi uma tentativa de controlar essa fluidez, bem como a fixação de zonas no PDDU de Passo Fundo. Ocorre que o intenso crescimento populacional, associado à industrialização sofrida pelos centros urbanos, tornou inviável a possibilidade de controlar esse processo, legando os problemas que os prognósticos da década de 1950 não previram ao presente.

RECEBIDO EM: 21/07/2015 APROVADO EM: 10/05/2016 